\title{
Phonographic spelling errors in developmental language disorder: Insights from executive functions
}

\author{
Marie-Pier Godin $^{1 *}$, Andréanne Gagné ${ }^{1}$, Nathalie Chapleau ${ }^{2}$
}

\begin{abstract}
The present study examined the executive functions and spelling performance of children with developmental language disorder (DLD) over a school year. Through a fine-grained spelling error analysis, we investigated whether the measured executive functions would distinguish children's spelling profiles. The study comprised three groups: the DLD-S group (aged 7-9 years), including children with DLD matched on the total number of spelling errors produced on a dictation task with a typically developing group $(n=8)$; the DLD-AM group (aged 79 years), including children with DLD matched on chronological age and phonological awareness skills with the DLD-S group $(n=8)$; and the typically developing group $(n=16$; aged 7-8 years). The results indicated that both DLD groups tended to produce more phonographic errors (i.e., spelling errors that change the phonology of the word) even if the DLD-S group produced a similar number of errors in comparison with the typically developing group. In particular, the DLD-AM group made more phoneme omissions than the other groups. The DLD-AM group also had the smallest spelling improvement over the school year and the weakest updating ability. In contrast, all groups had similar inhibition and cognitive flexibility abilities. This may indicate that some children with DLD present limitations in updating, which may lead to a slower spelling acquisition and a greater number of phonographic errors. Language impairments affect and delay spelling acquisition, and the presence of an updating deficit may exacerbate this delay.
\end{abstract}

\footnotetext{
${ }^{1}$ Université du Québec à Montréal, Faculty of Education Sciences, Department of Language Didactics, Montreal, Canada

${ }^{2}$ Université du Québec à Montréal, Faculty of Education Sciences, Department of Specialized Education and Training

*Author email address: godin.marie-pier@uqam.ca
}

To cite this article: Godin, M.-P., Gagné, A., \& Chapleau, N. (2018). Phonographic spelling errors in developmental language disorder: Insights from executive functions. Neuroeducation, 5(2), 46-61.

DOI: https://doi.org/10.24046/neuroed.20180502.46

Received on November $1^{\text {st }}, 2017$. Received in revised form on April $28^{\text {th }}, 2018$.

Accepted on May $10^{\text {th }}, 2018$. Available online on September $19^{\text {th }}, 2018$.

Neuroeducation, 5(2), 46-61

ISSN: 1929-1833

All rights reserved (C) 2018 - Association for Research in Neuroeducation 


\section{Introduction}

Developmental language disorder (DLD), formerly called specific language impairment (SLI), refers to a disorder affecting oral language despite the absence of a mental or physical handicap, hearing impairment, or environmental deprivation (Bishop et al., 2017; Bishop et al., 2016; Leonard, 2014). It is generally acknowledged that language impairments are associated with difficulties in literacy acquisition (Bishop \& Adams, 1990; Nash et al., 2013). There is also growing evidence that executive functioning (EF) may be involved in the problems characterizing language impairments and could be affected in children with DLD (Henry, Messer, \& Nash, 2011; Montgomery, Magimairaj, \& Finney, 2010; Pauls \& Archibald, 2016). The components of EF, or executive functions (EFs), are described as a set of higher order cognitive processes responsible for purposeful and goaldirected behaviours (Jurado \& Rosselli, 2007; Miyake et al., 2000). EFs are generally associated with writing performance (Altemeier et al., 2006; Berninger, Garcia, \& Abbott, 2009; Drijbooms, Groen, \& Verhoeven, 2015; Hooper et al., 2002; Roebers \& Jäger, 2014) and could discriminate skilled from less skilled spellers (Altemeier, Abbott, \& Berninger, 2008; Altemeier et al., 2006; Roebers \& Jäger, 2014; Walda et al., 2014). However, research on EFs and spelling acquisition in children with DLD is still limited.

\subsection{Executive functions in children with DLD}

Three of the most frequently identified EF components are inhibition, cognitive flexibility, and updating (Diamond, 2013; Miyake et al., 2000). Inhibition is the ability to stop prepotent or ongoing responses (Ibid.), whereas cognitive flexibility, also referred to as shifting, represents the ability to switch or adapt the focus of attention between tasks or problemsolving strategies (Miyake \& Friedman, 2012; Miyake et al., 2000). As for updating, it refers to the ability to monitor and code task-relevant incoming information. Updating also involves mentally working with information held in mind (Best, Miller, \& Jones, 2009; Diamond, 2013; Miyake et al., 2000).

Previous studies have shown inconsistent results regarding inhibition deficits in children with DLD. Some studies (Bishop \& Norbury, 2005; Ebert \& Kohnert, 2011; Finneran, Francis, \& Leonard, 2009; Henry et al., 2011; Pauls \& Archibald, 2016; Spaulding, 2010) pointed out difficulties in children with DLD compared to their typically developing (TD) peers, whereas other studies (Hanson \& Montgomery, 2002; Lukács et al., 2016; Marton et al., 2012; Noterdaeme et al., 2001) did not demonstrate differences between these groups. This divergence could be due to the various tasks used to measure inhibition (Pauls \& Archibald, 2016). Many of these tasks involved language, and it becomes difficult to dissociate language impairments from inhibition deficits.

Inconsistent results have also been observed regarding cognitive flexibility deficits. Some studies pointed out difficulties in children with DLD in comparison with TD children, specifically for tasks involving multivalent stimuli and multiple dimensional shifts (Marton, 2008; Vugs et al., 2013; Weyandt \& Willis, 1994). In contrast, other studies did not show that cognitive flexibility was deficient in children with DLD (Dibbets, Bakker, \& Jolles, 2006; Henry et al., 2011; Im-Bolter, Johnson, \& Pascual-Leone, 2006). As shown by Pauls and Archibald's (2016) meta-analysis, most of the tasks used to assess cognitive flexibility included verbal demands, and differences between DLD and TD children, if any, were probably due to language impairments.

Studies on children with DLD have focused more on updating given the strong links between working memory, language, and phonological skills (Montgomery, 2002; Montgomery et al., 2010). Many studies (e.g., Archibald \& Gathercole, 2006, 2007; Archibald \& Joanisse, 2009; Botting \& Conti-Ramsden, 2001; Graf Estes, Evans, \& Else-Quest, 2007; Montgomery et al., 2010) have shown important phonological loop limitations in the working memory in children with DLD. This phonological loop refers to the ability to temporarily store verbal information and it is generally measured by nonword repetition tasks (Montgomery et al., 2010). A recent metaanalysis (Vugs et al., 2013) has shown that working memory deficits may extend to the visuospatial domain. However, difficulties not only appear in the ability to temporarily store information, but also in its manipulation. In fact, in the DLD population, many children exhibit limitations in updating (Archibald \& Gathercole, 2006, 2007; Archibald, Joanisse, \& Edmunds, 2011; Bishop, 2006; Henry et al., 2011; Im-Bolter et al., 2006; Marton, 2008; Montgomery et al., 2010). Nonetheless, not all children with DLD present updating limitations (Archibald \& Joanisse, 2009). Considering that EF supports spelling, it would be relevant to examine the spelling development and the different spelling profiles of children with DLD, and to determine whether these profiles are only driven by their language abilities or by their EF as well. Before explaining the links between EF and spelling, spelling performance in children with DLD will be presented.

\subsection{Spelling in children with DLD}

Many studies pointed out that children with DLD are highly at risk of developing spelling delays (e.g., Cordewener, Bosman, \& Verhoeven, 2012; Nauclér, 2004; Snowling, Bishop, \& Stothard, 2000). Children with DLD generally produce more spelling errors than their TD peers with the same chronological age (e.g., Broc et al., 2013; Cordewener et al., 2012; Nauclér, 2004; Larkin, Williams, \& Blaggan, 2013). However, little is known about the error types produced. It is therefore difficult to confirm whether the error types made by DLD children are similar to or different from those made by TD children. Furthermore, few studies on children with DLD have examined spelling skills from a developmental perspective (e.g., Cordewener et al., 2012; Nauclér, 2004). Using one-time measurements does not allow for examining the evolution of the error types produced. In contrast, a longitudinal data collection contributes to a better understanding of the delay 
in spelling acquisition in the DLD population. To our knowledge, no study has examined French spelling acquisition in a longitudinal manner in children with DLD.

In order to better understand French spelling acquisition, it is important to note that French orthography is based on transcribing phonemes into graphemes (Jaffré \& Fayol, 2006; Perfetti, 1997). Oral language abilities and, more precisely, phonological skills are crucial for a good phonographic information transcription. In French, the writing system is coded with phonographic, orthographic, and morphographic information (Jaffré \& Fayol, 2006), but, this manuscript only focuses on the phonographic dimension.

Previous studies showed that children with DLD tend to produce more phonographic errors (i.e., phonologically unacceptable errors) than their TD peers (Bishop \& Clarkson, 2003; Broc et al., 2013; Larkin et al., 2014; Larkin \& Snowling, 2008; Nauclér, 2004), and more phonographic errors than younger children matched on spelling age (Larkin et al., 2013), on reading age (Larking \& Snowling, 2008), or on vocabulary level (Bishop \& Clarkson, 2003). Phonographic errors are spelling productions that change the phonology of the word. In contrast, TD children tend to produce more orthographic errors (i.e., phonologically acceptable errors), in which incorrect but plausible graphemes represent the phonology of the word. For example, in English, for the word card, an orthographic error could be kard, whereas a phonographic error could be gard. In French, for the word chaise $/ \int \varepsilon z /$, an orthographic error could be *chaize $/ \int \varepsilon z /$, and *chège $/ \int \varepsilon 3 /$ would be a phonographic error.

Phonographic errors are generally associated with weak or immature phonological awareness skills (Bishop \& Clarkson 2003). These errors tend to persist in the productions of children with DLD until adolescence (Nauclér, 2004). Some studies (Bishop \& Clarkson, 2003; Brizzolara et al., 2011; Larkin \& Snowling, 2008) hypothesize that an updating capacity deficit could also explain these phonographic errors in children with DLD, but no analysis was done to confirm this hypothesis. Observed types of phonographic errors include phoneme substitutions, omissions, and additions (Apel \& Masterson, 2001; Fayol, 2008; Masterson \& Apel, 2000, 2010). Only a single study (Nauclér, 2004) has examined these error types in the phonographic dimension in children with DLD, and it targeted Swedish language. However, it is important to note that some studies (e.g., Mackie \& Dockrell, 2004; Mackie, Dockrell, \& Lindsay, 2012; Silliman, Bahr, \& Peters, 2006) observed omissions, but in the morphographic dimension. These studies show that children with DLD tend to omit more frequently inflectional morphemes in their spelling attempts (e.g. the regular past tense morpheme -ed, the progressive ing morpheme, or the third person singular form - s). In sum, a limited number of studies have observed phonographic error types in children with DLD, and none of them in French. Consequently, spelling performance comprehension in the phonographic dimension is limited. Phonographic errors are generally associated to weak phonological awareness skills (Bishop \& Clarkson, 2003), but some studies (Bishop \&
Clarkson, 2003; Brizzolara et al., 2011; Larkin \& Snowling, 2008) suggest that they could also be associated to updating deficits - an EF component.

\subsection{Links between executive functions and spelling}

EF abilities are responsible for directing, adapting, switching, and monitoring tasks (Miyake et al. 2000), and contribute to writing and spelling productions (Altemeier et al., 2006; Åsberg Johnels, Kopp, \& Gillberg, 2014; Berninger et al., 2009). Most studies examining EF components and their links with spelling analyzed written language skills in a general manner (Hooper et al., 2010; Roebers \& Jäger, 2014; Röthlisberger et al., 2013), and showed that inhibition and cognitive flexibility explained variance in reading and writing performance (Altemeier et al., 2008) without describing each component's role. Nonetheless, few studies established links between each component and spelling acquisition.

With regard to spelling acquisition, inhibition and cognitive flexibility have received substantially less attention in research than updating. Studies suggest that inhibition capacity could suppress irrelevant information, such as phoneme or grapheme representations, and allow for an efficient retrieval of the relevant representations from longterm memory (Altemeier et al., 2008; Kellogg et al., 2013; Ribaupierre, 2002). In contrast, cognitive flexibility allows for switching from an inhibited representation set to an activated one (Kellogg et al., 2013).

Updating capacity plays a central role in the writing process (Berninger et al., 2009) and is involved in spelling acquisition (Caravolas, Hulme, \& Snowling, 2001; Lervåg \& Hulme, 2010; Stage \& Wagner, 1992). Updating enables spellers to maintain phoneme sequences in working memory and to keep track of the accurate and correctly ordered correspondences between phonemes and graphemes. Consequently, spelling represents a heavy processing task for working memory (Lervåg \& Hulme, 2010) and EFs appear to be involved in spelling acquisition. If this set of EF abilities fails, spelling is hampered, and it could also lead to a greater proportion of phonographic errors (Bishop \& Clarkson, 2003; Brizzolara et al., 2011; Larkin \& Snowling, 2008).

To our knowledge, no studies on children with DLD have tried to establish spelling profiles in the phonographic dimension and to examine EF in these different profiles, although several studies pointed out a delay in spelling acquisition (e.g., Cordewener et al., 2012; Nauclér, 2004; Snowling et al., 2000). Language impairments could explain this delay, but limitations in EF could as well. By comparing different groups of children with DLD who have similar language abilities, and by examining more closely the error types, it is possible to determine whether there is a difference in EF components between the DLD groups and whether it corresponds to a difference in spelling profiles. In combination with a longitudinal design, it may also be possible to compare the evolution of spelling skills and find out which abilities underlie the spelling delay of children with DLD. 


\subsection{The present study}

The present study examined the EF and spelling performance of children with DLD throughout a school year. The study comprised three groups: (a) DLD children matched on the total number of spelling errors produced on a dictation task with TD children; (b) DLD children matched with the other DLD children on chronological age and phonological awareness skills but producing a greater number of spelling errors; and (c) TD children. Outlined below are the four goals of this study.

Our first goal was to examine and compare EF between the three groups: Do the measured EF components differ between groups depending on their language abilities and spelling skills? We predicted that both DLD groups would perform similarly to TD children on cognitive flexibility and inhibition tasks based on previous studies (e.g., Dibbets et al., 2006; Finneran et al., 2009; Hanson \& Montgomery, 2002; Henry et al., 2011; Im-Bolter et al., 2006). However, we expected that both DLD groups would have lower scores than TD children on the updating measure (Archibald et al., 2011; Bishop, 2006; Montgomery et al., 2010), but that differences would be found between the DLD groups (Archibald \& Joanisse, 2009), with weaker spellers having weaker updating abilities (Bishop \& Clarkson, 2003; Larkin \& Snowling, 2008; Roebers \& Jäger, 2014).

Our second goal was to compare the evolution of spelling performance throughout the school year between the three groups: Does spelling performance evolve differently between groups in terms of the number of spelling errors produced? Based on their language abilities, we expected that TD children would make greater and faster progress in spelling than the two DLD groups.

Our third goal was to compare the proportions of phonographic errors between the three groups: Regardless of their differences in spelling performance, do the groups differ in the proportion of phonographic errors made? Based on previous studies (Larkin \& Snowling, 2008; Larkin et al., 2013; Nauclér, 2004), we predicted that both DLD groups would produce phonographic errors in greater proportion than their TD peers.

Our last goal was twofold. First, we wanted to examine the types of phonographic errors made by each group based on a fine-grained coding system. Second, we aimed to determine whether the observed patterns of phonographic errors differed between the three groups: Do spelling error patterns emerge in each group and if so, do they differ between groups? We predicted that the phonographic errors made by TD children would most likely be phoneme substitutions. In contrast, we hypothesized that both DLD groups would produce a wider range of error types (i.e., phoneme substitutions, omissions, and additions), which would reflect their inaccurate and unstable phonological representations (Zourou et al., 2010).
In sum, these group comparisons are relevant in two main respects. First, comparing TD children and peers with DLD who make a comparable number of spelling errors allows to determine whether the spelling errors are qualitatively similar between these groups. Second, a comparison between two DLD groups of the same chronological age and with similar phonological awareness skills also allows to observe potential qualitative differences in spelling errors. Importantly, this comparison enables us to observe whether the weaker spellers have weaker EF abilities.

\section{Method}

\subsection{Participants}

The 32 participants attended French schools in the suburbs of Montreal, Quebec, Canada, and had French as their first language. On the Test of Nonverbal Intelligence (TONI-3: Brown, Sherbenou, \& Johnsen, 1997), they all obtained scores within normal limits (i.e., standard scores above 85). All participants were in second grade and none received an intensive training on spelling. According to the teachers, around one hour per week was devoted to spelling. Half were children with DLD, and the other half were TD children. Children with DLD were further divided into two groups of eight participants based on the number of spelling errors produced on a dictation task (the DLD-S and DLD-AM groups). Descriptive statistics are presented in Table 1.

\section{Children with DLD}

In the province of Quebec, many students with DLD attend special language classes (ministère de l'Éducation, du Loisir et $\mathrm{du}$ Sport, 2008) and receive specialized instruction in groups smaller than those in mainstream education. Our sample consisted of 16 children (3 girls, 13 boys) who attended a special language class. Only children with a diagnosis of DLD made by a speech-language pathologist were included. Two had also been diagnosed with childhood apraxia of speech (CAS). Deaf and hearing-impaired children, as well as children with attention deficit hyperactivity disorder (ADHD) and autism syndrome disorder (ASD), were excluded from this study.

As shown in Table 1, the DLD-S and DLD-AM groups were matched on chronological age and phonological awareness skills but differed in the total number of spelling errors produced on an experimental dictation, with the DLD-S group performing significantly better on this dictation and producing less errors. The DLD-S group was matched with the TD group on the total number of spelling errors produced on the experimental dictation. No match on gender was done.

\section{TD children}

The 16 TD children were recruited from mainstream classrooms. This sample consisted of eight girls and eight boys, none of whom had been diagnosed with any learning disability. As mentioned, this group was matched with the DLD-S group on the total number of spelling errors produced on the experimental dictation. TD children had significantly higher scores on the phonological awareness task than both DLD groups. 
Table 1. Median $(\mathrm{M} d n)$ and range of ages, standardized measures, and performance on the experimental dictation for the three participant groups.

\begin{tabular}{|c|c|c|c|c|c|c|c|c|}
\hline \multirow[t]{2}{*}{ Measures } & \multicolumn{2}{|c|}{$\begin{array}{c}\text { TD } \\
(n=16)\end{array}$} & \multicolumn{2}{|c|}{$\begin{array}{l}\text { DLD-S } \\
(n=8)\end{array}$} & \multicolumn{2}{|c|}{$\begin{array}{l}\text { DLD-AM } \\
(n=8)\end{array}$} & \multicolumn{2}{|c|}{$\begin{array}{c}\text { Group } \\
\text { comparison }\end{array}$} \\
\hline & $\mathrm{Mdn}$ & range & $\mathrm{Mdn}$ & range & $\mathrm{Mdn}$ & range & $\chi^{2}(2)$ & $p$ \\
\hline $\begin{array}{l}\text { Chronological age } \\
\text { (years; months) }\end{array}$ & $7 ; 08_{a}$ & $7 ; 02-8 ; 03$ & $8 ; 05$ & $7 ; 04-9 ; 00$ & $8 ; 07_{b}$ & $7 ; 04-9 ; 03$ & 10.5 & .005 \\
\hline $\begin{array}{l}\text { Nonverbal intelligence } \\
\text { (TONI-3, standard score) }\end{array}$ & $97.0_{a}$ & $85.0-124$ & 92.5 & $85.0-100$ & $87.0_{\mathrm{b}}$ & $85.0-97.0$ & 11.7 & .001 \\
\hline $\begin{array}{l}\text { Phonological awareness } \\
\text { (CELF-CDN-F) }\end{array}$ & $63.0_{a}$ & $49.0-76.0$ & $45.5_{\mathrm{b}}$ & $30.0-67.0$ & $44.5_{\mathrm{b}}$ & $38.0-57.0$ & 13.4 & .001 \\
\hline $\begin{array}{l}\text { Spelling skills } \\
\text { Experimental dictation } \\
\text { (number of errors) }\end{array}$ & $38.0_{a}$ & $18.0-55.0$ & $41.5 \mathrm{a}$ & $20.0-52.0$ & $53.5_{b}$ & $49.0-70.0$ & 12.9 & .002 \\
\hline
\end{tabular}

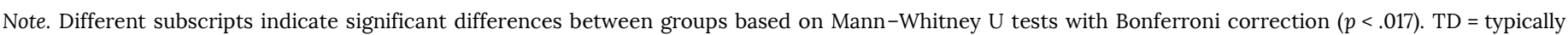

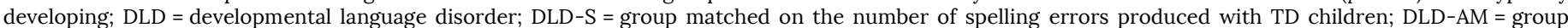

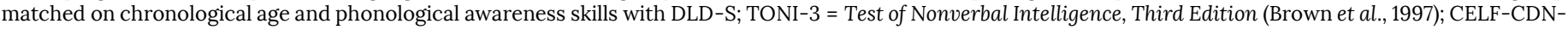
$\mathrm{F}=$ French Canadian version of the Clinical Evaluation of Language Fundamentals, Fourth Edition (Wiig et al., 2009).

\subsection{Measures}

Nonverbal intelligence and phonological awareness

Nonverbal intelligence and phonological awareness were assessed using standardized tests and used as control measures. The tests were administered and scored according to the procedures outlined in the test manuals. To assess nonverbal intelligence, the TONI-3 (Brown et al., 1997) was used. This language-free test measures intelligence, abstract reasoning, and problem solving. To assess phonological awareness skills, the Phonological Awareness subtest from the French-Canadian version of the Clinical Evaluation of Language Fundamentals, Fourth Edition (CELF-CDN-FR: Wiig et al., 2009) was used. Participants were administered 11 graduated tasks of syllable and phoneme manipulations. The test ended when participants failed all the items in a task or succeeded only once during three consecutive tasks.

Executive functions

Three EF components were assessed: updating, cognitive flexibility, and inhibition. All standardized tests corresponded to the participants' age range and were administered according to the procedures in the manuals. To assess updating capacity, the Digit Recall subtest from the French version of the Children's Memory Scale (CMS: Cohen, 2001) was used. There were two parts in this test, and two practice items were given before each part. In the first part, participants were asked to repeat digit strings forward. The first two strings contained two digits, the following two contained three digits, and so on, up to a maximum of nine digits. One point was given for each correctly repeated string (max. 18 points). This part ended when participants failed two consecutive items with the same number of digits. The second part of the test consisted in repeating digit strings backward. This part followed the same procedure as the first one, except that the maximum string length was eight digits, for a maximum of 16 points. On the one hand, the first part of this task measured more specifically the ability to temporarily store verbal information (i.e. the phonological loop). On the other hand, the second part targeted the capacity to maintain and manipulate verbal information held in mind, which is more in line with verbal working memory and updating capacities. A total score (max. 34 points) and subtotals for the two parts were obtained.

To assess cognitive flexibility, the Animal Sorting subtest from the French version of the Developmental Neuropsychological Assessment, Second Edition (NEPSY-II: Korkman, Kirk, \& Kemp, 2012) was used. In this test, participants were asked to sort eight picture cards of animals into two groups of four. No reading or expressive language was required to complete the task. In six minutes, participants had to do as many different sorts as possible. The number of correct sorts and the number of errors were counted.

Finally, to assess inhibition capacity, the Walk Don't Walk subtest from the French version of the Test of Everyday Attention for Children (TEA-Ch: Manly et al., 1999) was used. On a sheet showing paths made up of footprints, participants had to move their pencil one step upon hearing a sound stimulus (the go tone). However, they had to stop if this stimulus was followed by an explosion noise (the no-go tone). The items included three to twelve steps, and the pace increased throughout the task. The test began with four practice items, followed by twenty test items. One point was given for each correctly inhibited sequence (max. 20 points). 
Spelling

To assess spelling skills, an experimental dictation was used. This dictation consisted of 45 isolated words including 11 frequent words, 10 regular words, 14 words with complex or contextual graphemes, and 10 words with a final silent letter. All items were selected based on oral and written frequencies from three lexical databases (i.e., MANULEX: Lété, SprengerCharolles, \& Colé, 2004; ÉOLE: Pothier \& Pothier, 2004; Échelle de vocabulaire oral de Préfontaine: Préfontaine \& Préfontaine, 1968). These databases provide word frequencies on a grade-level basis, and all chosen items were of equivalent Grade 2 frequencies. Items were presented in a random order at each time of measurement. The experimenter said the target word, then said it in a sentence, and then repeated it again in isolation (e.g., Girafe. Mon animal préféré est la girafe. Girafe. [Giraffe. My favourite animal is the giraffe. Giraffe.]). The number of spelling errors was calculated.

To determine if qualitative differences in spelling errors were evident between groups, each error from the experimental dictation was coded. A fine-grained coding system inspired by previous studies (Fayol, 2008; Masterson \& Apel, 2000, 2010) was used. Such an approach allows to examine linguistic factors that lead to different spelling error types (Fayol, 2008; Masterson \& Apel 2000, 2010). Spelling errors were divided into phonographic and orthographic errors. As a reminder, phonographic errors are spelling productions that change the phonology of the word, whereas orthographic errors contain incorrect but plausible graphemes that represent the phonology of the word. In the present study, we examined the types of phonographic errors made by children. Three types of phonographic errors were distinguished: phoneme substitution, phoneme omission, and phoneme addition. Examples for each of them are provided in Table 2. A spelling error could be associated with only one type of phonographic error. Percentages of phonographic errors (among all spelling errors) and phonographic error types (among all phonographic errors) were calculated to examine how participants differed in the proportion of phonographic errors made, and to deeply analyze qualitative differences between groups in phonographic terms.

Table 2. Fine-grained analysis of phonographic spelling errors

\begin{tabular}{ll}
\hline $\begin{array}{l}\text { Type of } \\
\text { phonographic } \\
\text { error }\end{array}$ & Description \\
\hline $\begin{array}{l}\text { Phoneme } \\
\text { substitution }\end{array}$ & $\begin{array}{l}\text { Spellings with a sound substituted by another } \\
\left.\text { (e.g., chaise }- \text { chège; } / \int \varepsilon z / \rightarrow / \int \varepsilon z /\right) .\end{array}$ \\
$\begin{array}{l}\text { Phoneme } \\
\text { omission }\end{array}$ & $\begin{array}{l}\text { Spellings with a sound omitted } \\
\left.\text { (e.g., chaise }- \text { chè; } / \int \varepsilon z / \rightarrow / \int \varepsilon /\right) .\end{array}$ \\
$\begin{array}{l}\text { Phoneme } \\
\text { addition }\end{array}$ & $\begin{array}{l}\text { Spellings with a sound added } \\
(\text { e.g., sortir }- \text { soritir; } / \text { SortiR } / \rightarrow / \text { soRitiR } /) .\end{array}$ \\
\hline
\end{tabular}

\subsection{Procedure}

All children participated with parental consent and were tested three times during the school year: in November (T1), February (T2), and May (T3). For control measures (nonverbal intelligence and phonological awareness) and for EF measures, each child was tested individually during two 45minute sessions in a separate room at T1. The experimental dictation was group-administered in classrooms at the three time points to examine the evolution of spelling performance. At each time point, this spelling test was administered in two sessions and word items were randomly listed to decrease the risk of a habituation effect. No feedback was provided to the students on the words after the dictations.

\section{Results}

Nonparametric tests were used to compare the three groups because of the small sample sizes. The Kruskal-Wallis test, the Mann-Whitney U test, and Friedman's ANOVA were used to provide comparisons between and within groups. A Bonferroni correction was applied when necessary. It is important to mention that the DLD-AM children obtained scores within normal limits for nonverbal intelligence (as seen in Table 1), but that they had a significantly lower score than those from the TD group. Therefore, comparisons between these two groups must be interpreted with great caution, considering that nonverbal intelligence may explain differences in other aspects of cognition and spelling performance.

\subsection{Executive functions}

To address our first research question and compare the three groups on their EF abilities, a series of Kruskal-Wallis tests were used. Mann-Whitney $U$ tests with Bonferroni correction $(p<.017)$ were applied to follow up significant results. Median scores and group comparisons are displayed in Table 3.

For the updating measure (total), a significant difference was found between the three groups. Mann-Whitney $U$ tests showed a significant difference between the TD and DLD-AM groups, $U=14.3, p<.001, r=.69$. No significant difference was noted between the TD and DLD-S groups, $U=4.84, p=.227$, $r=.28$. The difference between the two DLD groups was not significant, $U=9.44, p=.042, r=.58$. However, given the large effect size, a larger sample could lead to a significant difference between the two DLD groups.

These differences between groups were maintained on both parts of the updating task (repeating digits forward or backward). TD children had significantly higher median scores than the DLD-AM group on the forward subtask, $\mathrm{U}=10.6, p=.006, r=.54$, and on the backward subtask, $\mathrm{U}=12.8, p=.001, r=.63$. No significant differences between the TD and DLD-S groups were observed on the forward subtask, $U=4.63, p=.236, r=.25$, and on the backward subtask, $\mathrm{U}=3.53, p=.369, r=.23$. The two DLD groups did 
not differ significantly on the forward subtask, $U=6.00$, $p=.183, r=.36$, and on the backward subtask, $U=9.31$, $p=.040, r=.63$. However, these medium and large effect sizes indicated that the differences between the two DLD groups could be significant with a larger sample. The three groups differed only on the updating measure. No significant differences were found between groups on the cognitive flexibility and inhibition measures. Whereas all groups performed similarly on the cognitive flexibility and inhibition tasks, the DLD-AM group had significantly lower performance on both parts of the updating task.

Table 3. Median $(\mathrm{Mdn})$ and range of executive function measures for the three participant groups

\begin{tabular}{|c|c|c|c|c|c|c|c|c|}
\hline \multirow{2}{*}{$\begin{array}{l}\text { Executive function } \\
\text { measures }\end{array}$} & \multicolumn{2}{|c|}{$\begin{array}{c}\text { TD } \\
(n=16)\end{array}$} & \multicolumn{2}{|c|}{$\begin{array}{l}\text { DLD-S } \\
(n=8)\end{array}$} & \multicolumn{2}{|c|}{$\begin{array}{l}\text { DLD-AM } \\
(n=8)\end{array}$} & \multicolumn{2}{|c|}{$\begin{array}{c}\text { Group } \\
\text { comparisons }\end{array}$} \\
\hline & $\mathrm{Mdn}$ & range & $\mathrm{Mdn}$ & range & $\mathrm{Mdn}$ & range & $\chi^{2}(2)$ & $p$ \\
\hline \multicolumn{9}{|l|}{ Updating (CMS) } \\
\hline Total & $10.0_{\mathrm{a}}$ & $8.00-15.0$ & 9.00 & $8.00-13.0$ & $7.00_{b}$ & $3.00-9.00$ & 12.7 & .002 \\
\hline Forward & $6.00_{\mathrm{a}}$ & $5.00-9.00$ & 5.50 & $5.00-8.00$ & $5.00_{\mathrm{b}}$ & $1.00-6.00$ & 7.50 & .024 \\
\hline \multicolumn{9}{|c|}{ Cognitive flexibility (NEPSY-II) } \\
\hline Number of correct sorts & 5.00 & $2.00-6.00$ & 5.00 & $3.00-7.00$ & 3.00 & $2.00-5.00$ & 3.81 & .149 \\
\hline Number of errors & 2.50 & $0.00-9.00$ & 3.00 & $1.00-13.0$ & 3.50 & $0.00-7.00$ & .664 & .717 \\
\hline
\end{tabular}

Note. Different subscripts indicate significant differences between groups based on Mann-Whitney U tests with Bonferroni correction $(p<.017)$. TD $=$ typically developing; DLD = developmental language disorder; DLD-S = group matched on spelling skills with TD children; DLD-AM = group matched on chronological age and phonological awareness skills with DLD-S; CMS = Children's Memory Scale, Digit Recall subtest (Cohen, 2001); NEPSY-II = Developmental Neuropsychological Assessment, Second Edition, Animal Sorting subtest (Korkman et al., 2012); TEA-Ch = Test of Everyday Attention for Children, Walk Don't Walk subtest (Manly et al., 1999). All subtests were French versions.

\subsection{Evolution of spelling performance}

To address our second research question and compare the three groups on their spelling performance, differences in the number of spelling errors made on the experimental dictation were analyzed using non-parametric tests. Median scores and group comparisons are displayed in Table 4 .

To examine the evolution of spelling performance in each group over the school year, a series of Friedman's ANOVAs were conducted. Results showed that TD children, $\chi^{2}(2)=19.6, p<.001$, the DLD-S group, $\chi^{2}(2)=9.75, p=.008$, and the DLD-AM group, $\chi^{2}(2)=6.75, \quad p=.034$, made significantly less spelling errors throughout the school year. To follow up these findings, Wilcoxon signed-rank tests with Bonferroni correction $(p<.017)$ were applied. Results revealed that the performance of the TD group improved significantly from T2 to T3, $Z=0.875, p=.001, r=.50$, and from $\mathrm{T} 1$ to $\mathrm{T} 3, \mathrm{Z}=-1.56, p<.001, r=.59$. No significant difference was noted from $\mathrm{T} 1$ to $\mathrm{T} 2, \mathrm{Z}=0.688, p=.052, r=.47$. The performance of the DLD-S group improved significantly from $\mathrm{T} 1$ to $\mathrm{T} 3, \mathrm{Z}=1.50, p=.003, r=.46$. No significant differences were found from $\mathrm{T} 1$ to $\mathrm{T} 2, \mathrm{Z}=0.375, p=.453$, $r=.10$, and from $\mathrm{T} 2$ to $\mathrm{T} 3, \mathrm{Z}=1.13, p=.024, r=.63$. In contrast, pairwise comparisons showed no significant difference for the DLD-AM group throughout the school year, from $\mathrm{T} 1$ to $\mathrm{T} 3, \mathrm{Z}=1.13, p=.024, r=.46$.
To compare the number of spelling errors between the three groups at each time of measurement, a series of KruskalWallis tests were used. Statistically significant differences between groups were observed at T1 and T3 (see Table 4). To follow up these results, Mann-Whitney $U$ tests with Bonferroni correction $(p<.017)$ were used. Results revealed that TD children produced significantly less spelling errors than the DLD-AM group at T1, $\mathrm{U}=-14.2, p<.001, r=.70$, and at T3, $\mathrm{U}=-11.2, p=.006, r=.53$. The DLD-S group produced a number of errors similar to that of TD children at T1, $\mathrm{U}=-1.47, p=.717, r=.08$, and at T3, $\mathrm{U}=-3.66, p=.368, r=.22$. The DLD-S group also produced significantly fewer errors than the DLD-AM group at T1, $\mathrm{U}=-12.7, p=.007, r=.68$. This significant difference was not maintained at $\mathrm{T} 3, \mathrm{U}=-7.56$, $p=.107, r=.47$. However, given the large effect size, a larger sample could show a significant difference between the two DLD groups.

In sum, these results showed that the TD and DLD-S groups produced a similar number of errors at each time of measurement during the school year, but TD children were those who progressed the most over the school year. In contrast, the DLD-AM group tended to produce significantly more spelling errors than the other two groups, and they made the least progress over the school year. 
Table 4. Median $(\mathrm{M} d n)$ and range of the number of spelling errors made on the experimental dictation for the three participant groups at the three times of measurement

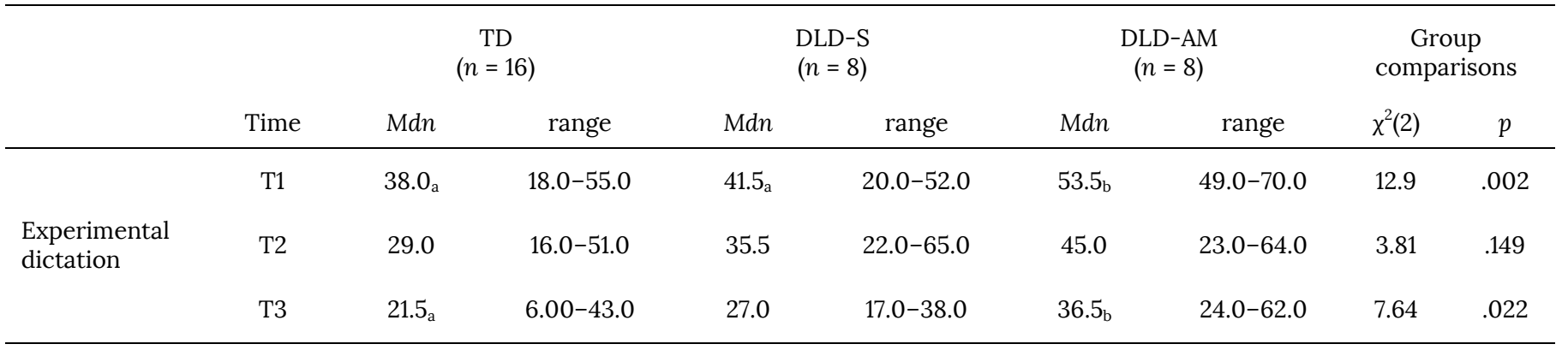

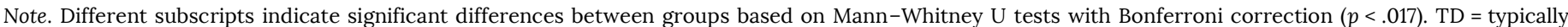

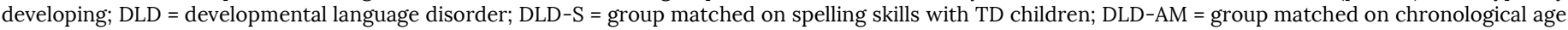
and phonological awareness skills with DLD-S; T1 = November; T2 = February; T3 = May (all in the same school year).

\subsection{Proportion of phonographic errors}

To address our third research question and compare the proportions of phonographic errors between the three groups, differences in the percentage of phonographic errors made on the experimental dictation were analyzed using non-parametric tests. Median percentages and group comparisons are displayed in Table 5.
First, to examine how the proportion of phonographic errors evolved in each group over the school year, a series of Friedman's ANOVAs were used. Results showed that the proportions of phonographic errors remained similar throughout the school year for TD children, $\chi^{2}(2)=3.88$, $p=.144$, for the DLD-S group, $\chi^{2}(2)=4.75, p=.093$, and for the DLD-AM group, $\chi^{2}(2)=4.75, p=.093$.

Table 5. Median (Mdn) and range of the percentage of phonographic errors among all spelling errors made on the experimental dictation for the three participant groups at the three times of measurement

\begin{tabular}{|c|c|c|c|c|c|c|c|c|c|}
\hline & \multirow[b]{2}{*}{ Time } & \multicolumn{2}{|c|}{$\begin{array}{c}\text { TD } \\
(n=16)\end{array}$} & \multicolumn{2}{|c|}{$\begin{array}{l}\text { DLD-S } \\
(n=8)\end{array}$} & \multicolumn{2}{|c|}{$\begin{array}{c}\text { DLD-AM } \\
(n=8)\end{array}$} & \multicolumn{2}{|c|}{$\begin{array}{c}\text { Group } \\
\text { comparisons }\end{array}$} \\
\hline & & $M d n$ & range & $\mathrm{M} d n$ & range & $\mathrm{Mdn}$ & range & $\chi 2(2)$ & $p$ \\
\hline \multirow{2}{*}{$\begin{array}{l}\text { Phonographic } \\
\text { errors }\end{array}$} & $\mathrm{T} 1$ & $29.9_{a}$ & $8.33-46.9$ & $34.9_{\mathrm{a}}$ & $20.0-40.0$ & $62.64_{b}$ & $57.1-75.7$ & 18.398 & $<.001$ \\
\hline & T3 & $33.2_{\mathrm{a}}$ & $0.00-51.2$ & 46.7 & $21.4-70.6$ & $50.24_{b}$ & $29.2-67.2$ & 6.884 & .032 \\
\hline
\end{tabular}

Note. Different subscripts indicate significant differences between groups based on Mann-Whitney U tests with Bonferroni correction $(p<.017)$. TD $=$ typically developing; DLD = developmental language disorder; DLD-S = group matched on spelling skills with TD children; DLD-AM = group matched on chronological age and phonological awareness skills with DLD-S; TC = combined data of T1, T2, T3; T1 = November; T2 = February; T3 = May (all in the same school year).

Second, as shown in Table 5, a series of Kruskal-Wallis tests showed that the proportions of phonographic errors were significantly different between groups at $\mathrm{T} 1, \mathrm{~T} 2$, and $\mathrm{T} 3$. Mann-Whitney U tests with Bonferroni correction $(p<.017)$ were used to follow up this finding. Results revealed that TD children produced significantly less phonographic errors than the DLD-AM group at the three times of measurement (T1, $U=-17.3, p<.001, r=.80 ; \mathrm{T} 2, \mathrm{U}=-14.9, p<.001, r=.76$; T3, $U=-9.81, p=.016, r=.51$ ). In contrast, over the school year, the TD and DLD-S groups tended to differ significantly (TC, $\mathrm{U}=-23.7, p=.001, r=.41$ ), more specifically at $\mathrm{T} 2$, $\mathrm{U}=-13.8, p=.001, r=.68$. However, no difference was noted at $\mathrm{T} 1, \mathrm{U}=-3.94, p=.332, r=.26$, and at $\mathrm{T} 3, \mathrm{U}=-7.19, p=.077$, $r=.34$. Finally, the proportions of phonographic errors between the two DLD groups only differed at T1, $\mathrm{U}=-13.4$, $p=.004, r=.84$, but not at T2, $\mathrm{U}=-1.13, p=.810, r=.03$, T3, $\mathrm{U}=-2.63, p=.576, r=.11$, or throughout the school year (TC, $\mathrm{U}=-18.5, p=.021, r=.36)$.

In sum, the TD and DLD-S groups produced fewer phonographic errors. In contrast, the DLD-AM group produced more phonographic errors. In fact, the spelling performance of the DLD-AM group was weaker than that of TD children throughout the school year. As for the two DLD 
groups, their performance was significantly different at $\mathrm{T} 1$ only. Even if the children in the DLD-S group had better spelling skills, their phonological representations still appeared to be fragile.

\subsection{Phonographic errors: A fine-grained analysis}

To address our fourth research question and compare the proportions of phoneme substitutions, omissions, and additions between the three groups, differences in the percentage of phonographic error types made on the experimental dictation were analyzed using non-parametric tests. Median percentages and group comparisons are displayed in Table 6.
To examine how the proportion of each type of phonographic error evolved in each group over the school year, a series of Friedman's ANOVA were used. Results showed that the percentages of phoneme substitutions of the TD group varied significantly over the year, $\chi^{2}(2)=8.40, p=.015$. Wilcoxon signed-rank tests with Bonferroni correction $(p<.017)$ showed that the percentages of substitutions increased significantly from $\mathrm{T} 1$ to $\mathrm{T} 2, \mathrm{Z}=-.938, p=.008, r=.29$, but not from $\mathrm{T} 1$ to $\mathrm{T} 3, \mathrm{Z}=-.188, p=.596, r=.15$, or from $\mathrm{T} 2$ to $\mathrm{T} 3$, $\mathrm{Z}=.750, p=.034, r=.32$. However, the percentages of phoneme substitutions remained similar for the DLD-S group, $\chi^{2}(2)=1.40, p=.497$ and for the DLD-AM group, $\chi^{2}(2)=.839, p=.657$.

Table 6. Median $(\mathrm{Mdn})$ and range of the percentage of phonographic error types among all phonographic errors made on the experimental dictation for the three participant groups at the three times of measurement

\begin{tabular}{|c|c|c|c|c|c|c|c|c|c|}
\hline \multirow{2}{*}{$\begin{array}{l}\text { Phonographic } \\
\text { error types }\end{array}$} & \multirow{2}{*}{ Time } & \multicolumn{2}{|c|}{$\begin{array}{c}\text { TD } \\
(n=16)\end{array}$} & \multicolumn{2}{|c|}{$\begin{array}{l}\text { DLD-S } \\
(n=8)\end{array}$} & \multicolumn{2}{|c|}{$\begin{array}{c}\text { DLD-AM } \\
(n=8)\end{array}$} & \multicolumn{2}{|c|}{$\begin{array}{c}\text { Group } \\
\text { comparisons }\end{array}$} \\
\hline & & $\mathrm{Mdn}$ & range & $\mathrm{Mdn}$ & range & $\mathrm{Mdn}$ & range & $\chi^{2}(2)$ & $p$ \\
\hline \multirow{4}{*}{ Substitutions } & $\mathrm{TC}$ & $78.2_{\mathrm{a}}$ & $0.00-100$ & $78.4_{a}$ & $41.7-92.9$ & $54.0_{\mathrm{b}}$ & $29.0-70.3$ & 31.5 & $<.001$ \\
\hline & $\mathrm{T} 1$ & $66.7_{\mathrm{a}}$ & $0.00-100$ & 69.5 & $41.7-85.7$ & $53.4_{\mathrm{b}}$ & $29.0-70.3$ & 6.62 & .037 \\
\hline & $\mathrm{T} 2$ & $89.4_{a}$ & $60.0-100$ & 68.6 & $45.5-92.9$ & $51.0_{\mathrm{b}}$ & $34.3-68.0$ & 14.4 & .001 \\
\hline & T3 & $78.4_{\mathrm{a}}$ & $0.00-100$ & $80.9 \mathrm{a}$ & $58.3-88.9$ & $54.0_{\mathrm{b}}$ & $46.2-66.7$ & 13.4 & .001 \\
\hline \multirow{4}{*}{ Omissions } & $\mathrm{TC}$ & $11.1_{a}$ & $0.00-46.7$ & $14.7 \mathrm{a}$ & $0.00-41.7$ & $36.7_{\mathrm{b}}$ & $16.7-58.1$ & 34.3 & $<.001$ \\
\hline & $\mathrm{T} 1$ & $13.6_{a}$ & $0.00-46.7$ & 23.0 & $0.00-41.7$ & $30.9_{b}$ & $24.3-58.1$ & 7.67 & .022 \\
\hline & $\mathrm{T} 2$ & $10.6_{a}$ & $0.00-40.0$ & 14.7 & $7.14-36.4$ & $36.0_{\mathrm{b}}$ & $16.7-53.6$ & 10.0 & .007 \\
\hline & T3 & $11.8_{\mathrm{a}}$ & $0.00-33.3$ & $11.4_{a}$ & $0.00-25.0$ & $42.5_{b}$ & $30.8-53.9$ & 16.4 & $<.001$ \\
\hline \multirow{4}{*}{ Additions } & $\mathrm{TC}$ & 0.00 & $0.00-100$ & 7.74 & $0.00-41.7$ & 5.20 & $0.00-26.1$ & 2.26 & .323 \\
\hline & $\mathrm{T} 1$ & 15.7 & $0.00-100$ & 8.57 & $0.00-41.7$ & 5.93 & $2.63-23.5$ & .124 & .940 \\
\hline & $\mathrm{T} 2$ & 0.00 & $0.00-17.7$ & 6.80 & $0.00-29.7$ & 4.20 & $0.00-26.1$ & 5.58 & .062 \\
\hline & T3 & 4.55 & $0.00-33.3$ & 9.89 & $0.00-16.7$ & 2.08 & $0.00-15.4$ & 1.50 & .471 \\
\hline
\end{tabular}

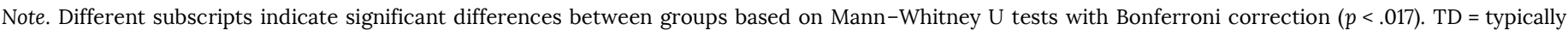

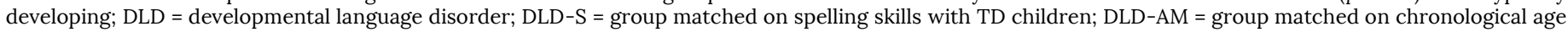
and phonological awareness skills with DLD-S; TC = combined data of T1, T2, T3; T1 = November; T2 = February; T3 = May (all in the same school year).

Regarding phoneme omissions, the percentages were relatively stable throughout the school year for TD children, $\chi^{2}(2)=1.09, \quad p=.581$, for the DLD-S group, $\chi^{2}(2)=.867$, $p=.648$, and for the DLD-AM group, $\chi^{2}(2)=1.23, p=.542$. Regarding phoneme additions, the percentages remained similar throughout the year for the DLD-S group, $\chi^{2}(2)=.207$, $p=.902$, and for the DLD-AM group, $\chi^{2}(2)=2.97, p=.227$. However, the percentages of phoneme additions of TD children varied significantly over the year, $\chi^{2}(2)=6.44$, $p=.040$, but Wilcoxon signed-rank tests with Bonferroni correction $(p<.017)$ did not reveal significant differences from $\mathrm{T} 1$ to $\mathrm{T} 2, \mathrm{Z}=.688, p=.052, r=.33$, from $\mathrm{T} 2$ to $\mathrm{T} 3$, $\mathrm{Z}=-.625, p=.077, r=.07$, and from $\mathrm{T} 1$ to $\mathrm{T} 3, \mathrm{Z}=.062$, $p=.860, r=.27$.

To compare the three groups on the proportion of phonographic error types at each time of measurement, a series of Kruskal-Wallis tests were used, and Mann-Whitney 
U tests with Bonferroni correction $(p<.017)$ were applied to follow up significant results. As shown in Table 6, for phoneme substitutions, significant differences between groups were observed at the three times of measurement. The DLD-S children (TC, $U=30.2, p<.0001, r=.6)$ and the TD children (TC, $\mathrm{U}=38.8, p<.0001, r=.63$ ) produced more phoneme substitutions over the school year in comparison with the DLD-AM children. No difference was noted between the DLD-S and the TD children (TC, $U=8.531, p=.220$, $r=.17)$. Specifically, the TD group produced, in a significantly greater proportion, more phoneme substitutions than the DLD-AM group at T1, $\mathrm{U}=9.84, p=.015, r=.48$, at $\mathrm{T} 2, \mathrm{U}=14.9$, $p<.001, r=.72$, and at T3, $U=13.8, p=.001, r=.67$. In contrast, the TD and DLD-S groups produced similar proportions of phoneme substitutions at T1, $\mathrm{U}=.031, p=.994$, $r=.019$, at $\mathrm{T} 2, \mathrm{U}=8.31, p=.040, r=.45$, and at $\mathrm{T} 3, \mathrm{U}=-.469$, $p=.908, r<.01$. The two DLD groups did not differ significantly at $\mathrm{T} 1, \mathrm{U}=9.81, p=.036, r=.55$, and at $\mathrm{T} 2$, $\mathrm{U}=6.63, p=.156, r=.42$. However, at $\mathrm{T} 1$, the large effect size indicated that the difference could be significant with a larger sample. At T3, the difference between these two groups was significant, $\mathrm{U}=14.3, p=.002, r=.80$.

For phoneme omissions, significant differences between groups were observed at the three times of measurement (see Table 6). The TD and the DLD-S groups produced similar proportions of phoneme omissions at T1, $\mathrm{U}=-3.06, p=.449$, $r=.18$, at $\mathrm{T} 2, \mathrm{U}=-3.00, p=.459, r=.21$, and at $\mathrm{T} 3, \mathrm{U}=-.219$, $p=.957, r=.03$. In contrast, the DLD-AM group produced, in a significantly greater proportion, more phoneme omissions than the TD group, at the three times of measurement (T1, $\mathrm{U}=-11.2, p=.006, r=.54 ; \mathrm{T} 2, \mathrm{U}=-12.8, p=.002, r=.58 ; \mathrm{T} 3$, $\mathrm{U}=-15.4, p<.001, r=.76)$. Over the school year, the two DLD groups differed in the proportion of phoneme omissions (TC, $\mathrm{U}=-33.7, p<.0001, r=.69)$. More specifically, at T3, a difference between these groups was observed, $U=-15.2$, $p=.001, r=0.84$, but no significant differences were noted at $\mathrm{T} 1, \mathrm{U}=-8.13, p=.082, r=.47$, and at $\mathrm{T} 2, \mathrm{U}=-9.75, p=.037$, $r=.64$. However, these large effect sizes indicated that differences could be significant with a larger sample.

Finally, for phoneme additions, no significant differences between groups were noted throughout the school year (see Table 6). In sum, the results showed that the DLD-AM group did more phonographic errors than the TD and DLD-S groups. In particular, the DLD-AM group did significantly more phoneme omissions all year long.

\section{Discussion}

The present study was conducted to investigate the EF and spelling performance of two groups of children with DLD in comparison with TD children: the DLD-S group, matched on the number of spelling errors produced with TD children, and the DLD-AM group, matched on chronological age and phonological awareness with the DLD-S group, but differing in the number of spelling errors produced. Results are discussed in relation to children's EF abilities, phonological awareness skills, and spelling profiles in the phonographic dimension.

\subsection{Executive functions in children with DLD}

Three EF components were assessed: inhibition, cognitive flexibility, and updating. Consistent with previous studies, all children with DLD performed similarly to TD children in the inhibition task (Finneran et al., 2009; Henry et al., 2011) and in the cognitive flexibility task (Dibbets et al., 2006; Henry et al., 2011; Im-Bolter et al., 2006). As a reminder, our inhibition and cognitive flexibility tasks did not involve expressive language. It is important to note that the TD group being approximately one year younger than the DLD groups, it probably highlighted some limits in these EF components in children with DLD. Comparing a TD group matched on chronological age with the DLD groups could be relevant to validate the presence of a delay in cognitive flexibility and inhibition. These results answered our first research question and supported our hypothesis, as no differences were found between groups for these two EF components. However, these components appeared to be fragile for the DLD groups.

As predicted, differences were observed only in the updating task. Many studies (Archibald \& Gathercole, 2006; Bishop, 2006; Montgomery et al., 2010) have demonstrated strong links between language impairments and working memory in children with DLD and hypothesized a deficit in this EF component. However, our results pointed out that it is not all children with DLD who present limitations in their updating capacity, as shown by Archibald and Joanisse (2009). Specifically, it was the children in the DLD-AM group who obtained the lowest scores on the updating task, whether it was on the forward subtask or on the backward one. Although their scores were significantly different only from TD children's scores, a significant difference could also appear between the two DLD groups given the medium and large effect sizes noted. Future studies including larger samples would be needed to confirm this hypothesis. In addition, as a reminder, it is important to note that the DLD-AM group had a lower score on the nonverbal intelligence task, even if it was within normal limits. This could explain the difference between the TD and DLD-AM groups in updating. Future studies should include a nonverbal intelligence matching procedure to better control this possible effect.

\subsection{Spelling performance and progress over the school year}

Even if children in the TD and DLD-S groups produced a similar number of spelling errors, our results showed that their error types could differ and that spelling profiles could be distinguished. Regarding our second research question, the three groups made progress and produced less spelling errors throughout the school year. However, TD children were those who progressed the most. These results supported our hypothesis and indicated that TD children's spelling skills would not remain similar to those of children in the DLD-S group throughout their academic years. Language impairments seem to hinder spelling development, and a 
delay was already noticeable in both DLD groups, particularly in the DLD-AM group.

We observed that the TD and DLD-S groups produced a similar number of spelling errors over the school year. It seems that the proportion of phonographic errors was also similar between these two groups at T1 (November) and T3 (May). At T2 (February), children in the DLD-S group produced more phonographic errors than TD children, and as many as their peers in the DLD-AM group. Therefore, to answer our third research question, results showed that qualitative variations could appear and differentiate the spelling profile of TD children from that of children with DLD-S.

Compared to TD children, children in the DLD-S group may have relied on other knowledge to spell so that they could achieve a quantitatively similar spelling performance. Children in the DLD-S group may have compensated their phonological difficulties by using a logographic procedure rather than an alphabetic procedure. Some children in the DLD-S group were older than TD children, and their greater exposure to written material could have contributed to their spelling performance. However, considering their weaker phonological awareness skills, their phonological representations remained unstable and inaccurate, as evidenced by their greater proportion of phonographic errors at $\mathrm{T} 2$.

\subsection{Phonological awareness skills and updating capacity in spelling performance}

Phonological awareness skills (Caravolas et al., 2001; Lervåg \& Hulme, 2010; Ouellette \& Sénéchal, 2008) and working memory (Lervåg \& Hulme, 2010; Stage \& Wagner, 1992) play a central role in spelling acquisition. Weak phonological awareness skills lead to phonographic errors (Bishop \& Clarkson, 2003). We observed this fact in both DLD groups, who tended to make more of these errors than their TD peers. We noted some differences in phonographic error type productions, and these differences did not seem to be only linked to phonological awareness skills.

First, phoneme substitution errors were produced in a larger proportion for each group compared to other error types. We observed that when the TD group produced substitutions, it was often due to the presence of a complex or contextual grapheme. For example, for the word girafe /ziraf/ (giraffe), a TD child who did not master the contextual grapheme $<\mathrm{g}>$, could have chosen another grapheme associated to this orthographic rule, thus also inadvertently affecting the phonology of the word, like in *guirafe /giraf/. This kind of substitution is more particularly associated to a lack of knowledge of the orthographic code rather than a symptom of weaker phonological awareness skills. In contrast, when the DLD groups produced phoneme substitutions, the children tended to choose phonemes close to the targeted ones (e.g., boulanger /bulanze/ - *poulancher /pulanfe/; argent /arzad/ - *azon /azon/). Their phoneme substitutions reflected a weaker phoneme manipulation.
Second, different spelling profiles emerged from the phoneme omission error proportions. Children in the DLDAM group were those who produced the largest proportion of phoneme omissions, all year long. In contrast, the other groups produced, anecdotally, some phoneme omissions at each time of measurement. It is interesting to note that the TD and DLD-S groups had similar updating capacities. We can hypothesize that children in the DLD-S group were more able to manipulate and update information in working memory than their peers in the DLD-AM group. Children in the DLD-S group seemed to be able, like their TD peers, to keep track of the coupling of phonemes to graphemes, without omitting phonemes, as evidenced by their smaller proportion of omissions. Their phoneme substitutions may hint at confusions with similar-sounding phonemes, rather than a weak phonological information manipulation in working memory. Therefore, it seems that their updating capacity supported their spelling, and their phonographic productions as predicted by previous studies (Bishop \& Clarkson, 2003; Brizzolara et al., 2011; Larkin \& Snowling, 2008).

On the other hand, considering that both DLD groups had similar phonological skills, it is difficult to argue that the greater proportion of phonographic errors made by children in the DLD-AM group (and, more precisely, their greater production of phoneme omissions) were due to their phonological impairments. In fact, it appears that children in the DLD-AM group presented limited updating capacity, as shown by their scores on the digit recall task. It is possible that their poorer updating capacity restrained their ability to maintain and segment a phonological sequence in working memory, and to associate each phoneme with the correct grapheme in the right order. Therefore, manipulating information in working memory seems to be more difficult for certain children with DLD, and this difficulty is likely to have led to the greater proportion of phoneme omissions observed in their spelling.

In addition, limited updating capacities could also lead to specific phoneme addition errors. Even if there were no difference in phoneme addition productions between the groups, these additions differed qualitatively. On the one hand, phoneme additions produced by the TD and DLD-S groups showed that they focus on the orthographic code and oversegment the phoneme structure (e.g., sortir /sortir/ *soretir /soratir/; partir /partir/- *paretir /paratir/). On the other hand, the DLD-AM group seemed to be overwhelmed by the phoneme-grapheme storage and processing, which led to illogical phoneme addition errors (e.g., beau, /bo/ - *bor, /bor/; cour /kur/ - *croure /krur/). Consequently, the DLD-AM phoneme additions and, more particularly, phoneme omissions highlight limited updating capacities which restrain the ability to maintain phoneme sequences in working memory, and to convert each phoneme into the right grapheme.

Children with DLD are generally able to manipulate phonological units in isolated and decontextualized tasks 
(Zourou et al., 2010). However, when they have to properly use and transfer these abilities in a complex and authentic task, like spelling words, they are experiencing difficulties. Spelling is not only a matter of maintaining a phonological sequence in working memory; it also implies a phoneme segmentation and a conversion of each correct phoneme into the correct grapheme stored in long-term memory. In the context of an isolated-word dictation-where cognitive resources are not required by processing syntactic structures, grammar, or the organization of ideas, as they would be in written text production-it appears that children in the DLD-AM group were already overwhelmed by the spelling task. Spelling represents a heavy processing task (Lervåg \& Hulme, 2010), even in a decontextualized form, because it draws on many cognitive and linguistic abilities simultaneously. Regarding spelling acquisition, our results help to clarify the updating capacity in children with DLD by suggesting that impairments in this EF component may have led to different spelling profiles and particular error patterns, such as a greater proportion of phoneme omissions. These results answered our fourth research question. Language impairments affect and delay the spelling development of children with DLD, and the presence of an updating deficit may exacerbate this delay. Future studies with larger samples would be needed to confirm this hypothesis and, as explained previously, a better control of nonverbal intelligence could be recommended.

Only a handful of studies have examined updating capacity in relation to spelling skills, and most of them targeted the TD children population (e.g., Caravolas et al., 2001; Lervåg \& Hulme, 2010). To our knowledge, the present study appears to be one of the first to distinguish spelling profiles in the DLD population, in relation to updating capacity. Our results suggest that weaker phonological awareness skills lead to a greater propensity for phonographic errors, and that weaker updating capacity does not allow for maintaining, manipulating, and correctly converting all phonemes into graphemes without omitting certain phonemes in spelling. Updating capacity could discriminate skilled from less skilled spellers, as shown by the examination of children's written productions (Roebers \& Jäger, 2014). In addition, through a longitudinal design, this study contributes to a better understanding of the delay in spelling acquisition of children with DLD. More longitudinal studies spanning longer periods are needed to clarify the nature of this delay.

\section{Conclusion}

The present study examined the EF and spelling performance of two groups of children with DLD in comparison with TD children. Our research showed that the three groups had similar EF abilities, except for the DLD-AM group which was weaker on the updating task. These difficulties probably led to the weaker spelling performance of children in the DLDAM group. These results help to clarify the updating capacity in children with DLD, and they suggest that impairments in this EF component possibly lead to different spelling profiles.

\subsection{Limitations}

There are two main limitations to the present study. First, larger samples would increase statistical power and allow for parametric analyses as well as correlation and regression analyses. Of note, the large and medium effect sizes reported here pointed to possible distinctions between the two DLD groups, and larger samples could lead to significant differences. Second, to measure updating, we used only a digit recall task, and that is not enough to get a global picture of children's updating capacities. Including additional updating tasks, such as verbal and nonverbal measures, could be relevant in future studies.

\subsection{Theoretical and clinical implications}

Our findings are in line with the view that children with DLD present a delay in spelling acquisition (Cordewener et al., 2012; Nauclér, 2004; Snowling et al., 2000). We highlight the possibility of an exacerbated delay linked to a deficit in updating capacity. Additional research is required to more fully understand how oral language and updating abilities influence spelling and its learning.

The overarching goal of the present study was to enhance our understanding of spelling performance. Our results indicate that children who exhibit language impairments and limitations in updating capacity tend to omit phonemes more frequently when spelling words, and that their phonological representations seem to be more fragile. Interventions should focus on the development of phonological awareness, but also on revision and rereading spelled words as strategies. In addition, it could be pertinent to guide children toward larger phonological units, such as morphemes, to develop their morphological awareness and enhance their spelling skills. Finally, future studies testing interventions that combine learning to spell and enhancing updating capacities could be relevant.

\section{References}

Altemeier, L. E., Abbott, R. D., \& Berninger, V. W. (2008). Executive functions for reading and writing in typical literacy development and dyslexia. Journal of Clinical and Experimental Neuropsychology, 30(5), 588-606. https://doi.org/10.1080/13803390701562818

Altemeier, L. E., Jones, J., Abbott, R. D., \& Berninger, V. W. (2006). Executive functions in becoming writing readers and reading writers: Note taking and report writing in third and fifth graders. Developmental Neuropsychology, 29(1), 161-173. https://doi.org/10.1207/s15326942dn2901_8

Apel, K., \& Masterson, J. J. (2001). Theory-guided spelling assessment and intervention: A case study. Language, Speech \& Hearing Services in Schools, 32(3), 182-195. https://doi.org/10.1044/0161-1461(2001/017) 
Archibald, L. M. D., \& Gathercole, S. E. (2007). The complexities of complex memory span: Storage and processing deficits in specific language impairment. Journal of Memory and Language, 57(2), 177-194. https://doi.org/10.1016/j.jml.2006.11.004

Archibald, L. M. D., \& Gathercole, S. E. (2006). Short-term and working memory in specific language impairment. International Journal of Language $\mathcal{E}$ Communication Disorders, 41(6), 675-693. https://doi.org/10.1080/13682820500442602

Archibald, L. M. D., \& Joanisse, M. F. (2009). On the sensitivity and specificity of nonword repetition and sentence recall to language and memory impairments in children. Journal of Speech, Language, and Hearing Research, 52(4), 899-914. https://doi.org/10.1044/1092-4388(2009/08-0099)

Archibald, L. M. D., Joanisse, M., \& Edmunds, A. (2011). Specific language or working memory impairments: A small scale observational study. Child Language Teaching \& Therapy, 27(3), 294-312. https://doi.org/10.1177/0265659010396779

Åsberg Johnels, J., Kopp, S., \& Gillberg, C. (2012). Spelling difficulties in school-aged girls with attentiondeficit/hyperactivity disorder. Journal of Learning Disabilities, 47(5), 424-434. https://doi.org/10.1177/0022219412467058

Berninger, V. W., Garcia, N. P., \& Abbott, R. D. (2009). Multiple processes that matter in writing instruction and assessment. In G. A. Troia (Ed.), Instruction and assessment for struggling writers: Evidence-based practices (pp. 15-50). New York, NY: Guilford Press.

Best, J. R., Miller, P. H., \& Jones, L. L. (2009). Executive functions after age 5: Changes and correlates. Developmental Review, 29(3), 180-200. https://doi.org/10.1016/j.dr.2009.05.002

Bishop, D. V. M. (2006). What causes specific language impairment in children? Current Directions in Psychological Science, 15(5), 217-221. https://doi.org/10.1111/j.1467-8721.2006.00439.x

Bishop, D. V. M., \& Adams, C. (1990). A prospective study of the relationship between specific language impairment, phonological disorders and reading retardation. Journal of Child Psychology and Psychiatry, 31(7), 1027-1050. https://doi.org/10.1111/j.1469-7610.1990.tb00844.x

Bishop, D. V. M., \& Clarkson, B. (2003). Written language as a window into residual language deficits: A study of children with persistent and residual speech and language impairments. Cortex, 39(2), 215-237. https://doi.org/10.1016/s0010-9452(08)70106-0
Bishop, D. V. M., \& Norbury, C. F. (2005). Executive functions in children with communication impairments, in relation to autistic symptomatology: II: Response inhibition. Autism, 9(1), 29-43. https://doi.org/10.1177/1362361305049028

Bishop, D. V. M., Snowling, M. J., Thompson, P. A., Greenhalgh, T. and the CATALISE-2 consortium. (2017). Phase 2 of CATALISE: A multinational and multidisciplinary Delphi consensus study of problems with language development: Terminology. Journal of Child Psychology and Psychiatry, 58(10), 1068-1080. https://doi.org/10.1111/jcpp.12721

Bishop, D. V. M., Snowling, M. J., Thompson, P. A., Greenhalgh, T. and CATALISE consortium (2016). CATALISE: A multinational and multidisciplinary Delphi Consensus study. Identifying language impairments in children. PLOS ONE, 11(7), e0158753. https://doi.org/10.1371/journal.pone.0158753

Botting, N., \& Conti-Ramsden, G. (2001). Non-word repetition and language development in children with specific language impairment (SLI). International Journal of Language E Communication Disorders, 36(4), 421-432. https://doi.org/10.1080/13682820110074971

Brizzolara, D., Gasperini, F., Pfanner, L., Cristofani, P., Casalini, C., \& Chilosi, A. M. (2011). Long-term reading and spelling outcome in Italian adolescents with a history of specific language impairment. Cortex, 47(8), 955-973. https://doi.org/10.1016/j.cortex.2011.02.009

Broc, L., Bernicot, J., Olive, T., Favart, M., Reilly, J., Quémart, P., \& Uzé, J. (2013). Lexical spelling in children and adolescents with specific language impairment: Variations with the writing situation. Research in Developmental Disabilities, 34(10), 3253-3266. https://doi.org/10.1016/j.ridd.2013.06.025

Brown, L., Sherbenou, R. J., \& Johnsen, S. K. (1997). Test of nonverbal intelligence (TONI-3). ( $3^{\text {rd }}$ ed.). Austin, TX: ProEd.

Caravolas, M., Hulme, C., \& Snowling, M. J. (2001). The foundations of spelling ability: Evidence from a 3-year longitudinal study. Journal of Memory and Language, 45(4), 751-774. https://doi.org/10.1006/jmla.2000.2785

Cohen, M. J. (2001). Échelle clinique de mémoire pour enfants (CMS). Toronto, ON: Pearson.

Cordewener, K. A. H., Bosman, A. M. T., \& Verhoeven, L. (2012). Specific language impairment affects the early spelling process quantitatively but not qualitatively. Research in Developmental Disabilities, 33(4), 1041-1047. https://doi.org/10.1016/j.ridd.2012.01.011 
Diamond, A. (2013). Executive functions. Annual Review of Psychology, 64(1), 135-168.

https://doi.org/10.1146/annurev-psych-113011-143750

Dibbets, P., Bakker, K., \& Jolles, J. (2006). Functional MRI of task switching in children with specific language impairment (SLI). Neurocase, 12(1), 71-79. https://doi.org/10.1080/13554790500507032

Drijbooms, E., Groen, M. A., \& Verhoeven, L. (2015). The contribution of executive functions to narrative writing in fourth grade children. Reading and Writing, 28(7), 9891011. https://doi.org/10.1007/s11145-015-9558-z

Ebert, K. D., \& Kohnert, K. (2011). Sustained attention in children with primary language impairment: A metaanalysis. Journal of Speech, Language, and Hearing Research, 54(5), 1372-1384. https://doi.org/10.1044/1092-4388(2011/10-0231)

Fayol, M. (2008). Les erreurs : manière d'appréhender la production orthographique. In M. Fayol, \& J.-P. Jaffré (Eds.), Orthographier (pp. 123-136). Paris, France: Presses universitaires de France.

Finneran, D. A., Francis, A. L., \& Leonard, L. B. (2009). Sustained attention in children with specific language impairment (SLI). Journal of Speech, Language, and Hearing Research, 52(4), 915-929. https://doi.org/10.1044/1092-4388(2009/07-0053)

Graf Estes, K., Evans, J. L., \& Else-Quest, N. M. (2007). Differences in the nonword repetition performance of children with and without specific language impairment: A meta-analysis. Journal of Speech, Language, and Hearing Research, 50(1), 177-195. https://doi.org/10.1044/1092-4388(2007/015)

Hanson, R. A., \& Montgomery, J. W. (2002). Effects of general processing capacity and sustained selective attention on temporal processing performance of children with specific language impairment. Applied Psycholinguistics, 23(1), 75-93. https://doi.org/10.1017/s0142716402000048

Henry, L. A., Messer, D. J., \& Nash, G. (2011). Executive functioning in children with specific language impairment. Journal of Child Psychology and Psychiatry, 53(1), 37-45. https://doi.org/10.1111/j.1469-7610.2011.02430.x

Hooper, S. R., Costa, L. J., McBee, M., Anderson, K. L., Yerby, D. C., Knuth, S. B., \& Childress, A. (2010). Concurrent and longitudinal neuropsychological contributors to written language expression in first and second grade students. Reading and Writing, 24(2), 221-252. https://doi.org/10.1007/s11145-010-9263-x

Hooper, S. R., Swartz, C. W., Wakely, M. B., de Kruif, R. E. L., \& Montgomery, J. W. (2002). Executive functions in elementary school children with and without problems in written expression. Journal of Learning Disabilities, 35(1), 57-68. https://doi.org/10.1177/002221940203500105
Im-Bolter, N., Johnson, J., \& Pascual-Leone, J. (2006). Processing limitations in children with specific language impairment: The role of executive function. Child Development, 77(6), 1822-1841. https://doi.org/10.1111/j.1467-8624.2006.00976.x

Jaffré, J.-P., \& Fayol, M. (2006). Orthography and literacy in French. In R. M. Joshi, \& P. G. Aaron (Eds.), Handbook of Orthography and Literacy (pp. 81-104). New Jersey: Lawrence Erlbaum Associates.

Jurado, M. B., \& Rosselli, M. (2007). The elusive nature of executive functions: A review of our current understanding. Neuropsychology Review, 17(3), 213-233. https://doi.org/10.1007/s11065-007-9040-z

Kellogg, R. T., Whiteford, A. P., Turner, C. E., Cahill, M., \& Mertens, A. (2013). Working memory in written composition: A progress report. Journal of Writing Research, 5(2), 159-190. https://doi.org/10.17239/jowr2013.05.02.1

Korkman, M., Kirk, U., \& Kemp, S. (2012). Bilan neuropsychologique de l'enfant (NEPSY-II) (2 ${ }^{\text {nd }}$ ed.). Toronto, ON: Pearson.

Larkin, R. F., \& Snowling, M. J. (2008). Comparing phonological skills and spelling abilities in children with reading and language impairments. International Journal of Language E Communication Disorders, 43(1), 111-124. https://doi.org/10.1080/13682820601178584

Larkin, R. F., Williams, G. J., \& Blaggan, S. (2013). Delay or deficit? Spelling processes in children with specific language impairment. Journal of Communication Disorders, 46(5-6), 401-412. https://doi.org/10.1016/j.jcomdis.2013.07.003

Leonard, L. B. (2014). Children with specific language impairment ( $2^{\text {nd }}$ ed.). Cambridge, MA: The MIT Press.

Lervåg, A., \& Hulme, C. (2010). Predicting the growth of early spelling skills: Are there heterogeneous developmental trajectories? Scientific Studies of Reading, 14(6), 485-513. https://doi.org/10.1080/10888431003623488

Lété, B., Sprenger-Charolles, L., \& Colé, P. (2004). MANULEX: A grade-level lexical database from French elementary school readers. Behavior Research Methods, Instruments, E Computers, 36(1), 156-166. https://doi.org/10.3758/bf03195560

Lukács, Á., Ladányi, E., Fazekas, K., \& Kemény, F. (2016). Executive functions and the contribution of short-term memory span in children with specific language impairment. Neuropsychology, 30(3), 296-303. https://doi.org/10.1037/neu0000232

Mackie, C. J., \& Dockrell, J. E. (2004). The nature of written language deficits in children with SLI. Journal of Speech, Language, and Hearing Research, 47(6), 1469-1483. https://doi.org/10.1044/1092-4388(2004/109) 
Mackie, C. J., Dockrell, J., \& Lindsay, G. (2012). An evaluation of the written texts of children with SLI: the contributions of oral language, reading and phonological short-term memory. Reading and Writing, 26(6), 865888. https://doi.org/10.1007/s11145-012-9396-1

Manly, T., Robertson, I. H., Anderson, V., \& Nimmo-Smith, I. (1999). TEA-Ch: Test d'évaluation de l'attention chez l'enfant. Toronto, ON : Pearson.

Marton, K. (2008). Visuo-spatial processing and executive functions in children with specific language impairment. International Journal of Language $\mathcal{E}$ Communication Disorders, 43(2), 181-200. https://doi.org/10.1080/16066350701340719

Marton, K., Campanelli, L., Scheuer, J., Yoon, J., \& Eichorn, N. (2012). Executive function profiles in children with and without specific language impairment. Journal of Applied Psycholinguistics, 12(3), 57-73. PMID: 25302062

Masterson, J. J., \& Apel, K. (2010). The spelling sensitivity score: Noting developmental changes in spelling knowledge. Assessment for Effective Intervention, 36(1), 35-45. https://doi.org/10.1177/1534508410380039

Masterson, J. J., \& Apel, K. (2000). Spelling assessment: Charting a path to optimal intervention. Topics in Language Disorders, 20(3), 50-65.

https://doi.org/10.1097/00011363-200020030-00007

Ministère de l'Éducation, du Loisir et du Sport (2008). Déclaration des effectifs scolaires, 2005-2006 et 20062007. Québec: Gouvernement du Québec.

Miyake, A., \& Friedman, N. P. (2012). The nature and organization of individual differences in executive functions: Four general conclusions. Current Directions in Psychological Science, 21(1), 8-14.

https://doi.org/10.1177/0963721411429458

Miyake, A., Friedman, N. P., Emerson, M. J., Witzki, A. H., Howerter, A., \& Wager, T. D. (2000). The unity and diversity of executive functions and their contributions to complex "frontal lobe" tasks: A latent variable analysis. Cognitive Psychology, 41(1), 49-100.

https://doi.org/10.1006/cogp.1999.0734

Montgomery, J. W. (2002). Understanding the language difficulties of children with specific language impairments: Does verbal working memory matter? American Journal of Speech-Language Pathology, 11(1), 7791. https://doi.org/10.1044/1058-0360(2002/009)

Montgomery, J. W., Magimairaj, B. M., \& Finney, M. C. (2010). Working memory and specific language impairment: An update on the relation and perspectives on assessment and treatment. American Journal of Speech-Language Pathology, 19(1), 78-94. https://doi.org/10.1044/10580360(2009/09-0028)
Nash, H. M., Hulme, C., Gooch, D., \& Snowling, M. J. (2013). Preschool language profiles of children at family risk of dyslexia: Continuities with specific language impairment. Journal of Child Psychology and Psychiatry, 54(9), 958968. https://doi.org/10.1111/jcpp.12091

Nauclér, K. (2004). Spelling development in Swedish children with and without language impairment. Journal of Multilingual Communication Disorders, 2(3), 207-215. https://doi.org/10.1080/14769670400018315

Noterdaeme, M., Amorosa, H., Mildenberger, K., Sitter, S., \& Minow, F. (2001). Evaluation of attention problems in children with autism and children with a specific language disorder. European Child \& Adolescent Psychiatry, 10(1), 58-66. https://doi.org/10.1007/s007870170048

Ouellette, G. P., \& Sénéchal, M. (2008). A window into early literacy: Exploring the cognitive and linguistic underpinnings of invented spelling. Scientific Studies of Reading, 12(2), 195-219. https://doi.org/10.1080/10888430801917324

Pauls, L. J., \& Archibald, L. M. D. (2016). Executive functions in children with specific language impairment: A metaanalysis. Journal of Speech, Language, and Hearing Research, 59(5), 1074-1086. https://doi.org/10.1044/2016_jslhr-1-15-0174

Perfetti, C. A. (1997). Psycholinguistique de l'orthographe et de la lecture. In L. Rieben, M. Fayol, \& C. A. Perfetti (Eds.), Des orthographes et leur acquisition (pp. 37-56). Lausanne/Paris: Delachaux et Niestlé.

Pothier, B., \& Pothier, P. (2004). Échelle d'acquisition en orthographe lexicale. Paris, France: Retz.

Préfontaine, R.-T., \& Préfontaine, G. (1968). Vocabulaire oral des enfants de 5 à 8 ans au Canada français: Méthodologie de l'enseignement de l'orthographe par la méthode "Le Sablier". Montreal, QC: Librairie Beauchemin.

Ribaupierre, A. D. (2002). Working memory and attentional processes across the lifespan. In P. Graf \& N. Ohta (Eds.), Lifespan development of human memory (pp. 59-80). Cambridge: MIT Press.

Roebers, C. M., \& Jäger, K. (2014). The relative importance of fine motor skills, intelligence, and executive functions for first graders' reading and spelling skills. Perspectives on Language and Literacy, 40(2), 13-17.

Röthlisberger, M., Neuenschwander, R., Cimeli, P., \& Roebers, C. M. (2013). Executive functions in 5- to 8-year olds: Developmental changes and relationship to academic achievement. Journal of Educational and Developmental Psychology, 3(2), 153-167. https://doi.org/10.5539/jedp.v3n2p153 
Silliman, E. R., Bahr, R. H., \& Peters, M. L. (2006). Spelling patterns in preadolescents with atypical language skills: Phonological, morphological, and orthographic factors. Developmental Neuropsychology, 29(1), 93-123. https://doi.org/10.1207/s15326942dn2901_6

Spaulding, T. J. (2010). Investigating mechanisms of suppression in preschool children with specific language impairment. Journal of Speech, Language, and Hearing Research, 53(3), 725-738. https://doi.org/10.1044/10924388(2009/09-0041)

Snowling, M., Bishop, D. V. M., \& Stothard, S. E. (2000). Is preschool language impairment a risk factor for dyslexia in adolescence? Journal of Child Psychology and Psychiatry, 41(5), 587-600. https://doi.org/10.1017/s0021963099005752

Stage, S. A., \& Wagner, R. K. (1992). Development of young children's phonological and orthographic knowledge as revealed by their spellings. Developmental Psychology, 28(2), 287-296. https://doi.org/10.1037//0012-1649.28.2.287

Vugs, B., Cuperus, J., Hendriks, M., \& Verhoeven, L. (2013). Visuospatial working memory in specific language impairment: A meta-analysis. Research in Developmental Disabilities, 34(9), 2586-2597.

https://doi.org/10.1016/j.ridd.2013.05.014
Walda, S. A. E., van Weerdenburg, M., Wijnants, M. L., \& Bosman, A. M. T. (2014). Progress in reading and spelling of dyslexic children is not affected by executive functioning. Research in Developmental Disabilities, 35(12), 3431-3454. https://doi.org/10.1016/j.ridd.2014.08.013

Weyandt, L. L., \& Willis, W. G. (1994). Executive functions in school-aged children: Potential efficacy of tasks in discriminating clinical groups. Developmental Neuropsychology, 10(1), 27-38. https://doi.org/10.1080/87565649409540564

Wiig, E. H., Secord, W. A., Semel, E., Boulianne, L., \& Labelle, M. (2009). Évaluation clinique des notions langagières fondamentales - version pour francophones du Canada (CELF-CDN-F). Toronto, ON : Pearson.

Zourou, F., Ecalle, J., Magnan, A., \& Sanchez, M. (2010). The fragile nature of phonological awareness in children with specific language impairment: Evidence from literacy development. Child Language Teaching and Therapy, 26(3), 347-358. https://doi.org/10.1177/0265659010369288 